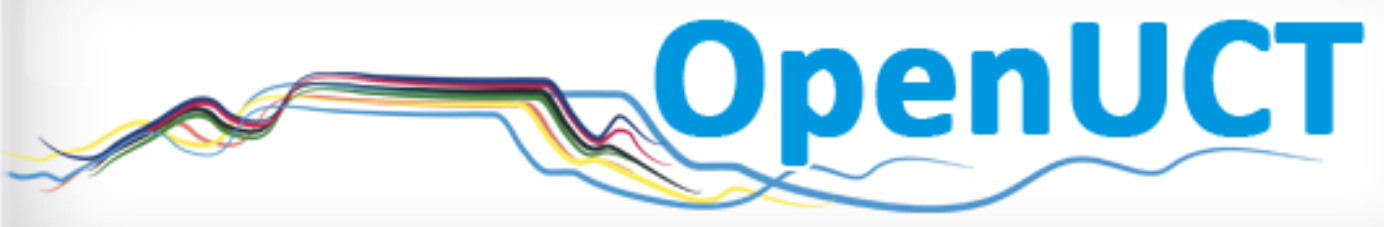

This is the author-approved manuscript version of a journal article published in:

Badenhorst, E. \& Kapp, R. 2013. Negotiation of learning and identity among first-year medical students. Teaching in Higher Education. 18(5): 465-476. DOI: 10.1080/13562517.2012.753050.

It is made available under the terms of agreement between the author and the journal, and in accordance with the University of Cape Town's Open Access Policy for the purposes of research, teaching and private study.

http://www.openuct.uct.ac.za/sites/default/files/UCTOpenAccessPolicy.pdf 


\title{
Negotiation of learning and identity among first-year medical students
}

\author{
Elmi Badenhorst \\ Department of Human Biology, Faculty of Health Sciences, University of Cape Town. \\ Email: elmi.badenhorst@uct.ac.za, \\ Rochelle Kapp \\ Centre for Higher Education, Academic Development Programme, University of Cape Town.
}

\begin{abstract}
The demand for medical schools to produce competent doctors to meet health needs in South Africa has increased. In response to this challenge, the Faculty of Health Sciences at a relatively elite university introduced a problem-based, socially relevant curriculum in 2002. The classroom environment is designed to facilitate a learning context where students from diverse backgrounds engage critically and learn from each other. This study draws on data from a larger qualitative case study to describe how a group of 'black' students who failed their first semester experienced the school-university transition. Drawing on post-structuralist theory, this article analyses how the students negotiated learning and identity. The argument is made that the students re-positioned themselves in deficit, outsider subject positions in order to survive their first year. This article ends with a consideration of the implications for developing a learning environment which recognises difference and fosters diversity.
\end{abstract}

Keywords: identity; diversity; problem-based learning; academic support programmes; medical students

\section{Introduction}

I did not even read my emails ... I was so, so aaah ... I did not even know the internet. I used to stay outside, I was not in res [student housing]. I had difficulties in cooking and balancing my work. . . . I did not even want to study, I just opened my books and see what is going on ....

These are the words of Sdu, a 'black' 1 first-year medical student who was a participant in a qualitative case study which traced the school to university transition of 100 students from a range of disciplines. Importantly, this particular cohort has grown-up and been educated in a 'new' South Africa under a single educational system, using a curriculum based on the principles of Outcomes-Based Education. Sdu was one of the top students in his working-class township school in 2008 . He had dreamt of becoming a medical doctor since childhood, and was thus ecstatic when he heard of his acceptance into one of the most prestigious Faculties of Health Sciences in the country. 
However, within the first two weeks at university, Sdu realised that he did not possess the 'cultural capital' (Bourdieu 1991, 230) deemed appropriate by the Faculty. He described how he went to a bookshop during his first month at university, but had no idea what to do there. Consequently, he followed a 'white' student whom he recognised from class and bought every book she bought. Once he returned to his room, he decided he could not comprehend what was written in the books. He came to the conclusion that since other students seemed able to read and discuss the material with confidence during group activities, the implication was that he basically 'had no voice'. Thereafter, he resorted to being silent in class and to rewriting and memorising chunks of the text books. He did not pass any assessments during his first semester and was placed in a year-long academic support (Intervention) programmez at the end of the semester.

This story captures the feelings of being overwhelmed, of helplessness, loneliness and of alienation, expressed in the narratives of the 13 'black' Health Science students who failed the first semester (in 2009) and who are the subject of this paper. Whereas previous studies of students from disadvantaged backgrounds in the Health Sciences context in South Africa have tended to focus on structural constraints and on the cognitive, learning and academic literacy difficulties, experienced by students (see, for example, Oberprieler, Masters, and Gibbs 2005; van Pletzen 2006; Olckers, Gibbs, and Duncan 2007; Sikakana 2010), this paper traces students' unfolding sense of self in relation to the new context. We describe the ways in which they make use of resources and their perceptions of barriers to learning. In doing so, we illustrate the ways in which they had to reconstruct a sense of self in relation to a very different learning and institutional environment over the course of their first year of university.

\section{Theoretical considerations}

We use a post-structuralist notion of 'discourse' to describe the accepted ways of 'saying-doing-being-valuing-believing' (Gee 1990, 142) that characterise particular contexts. The basic premise of post-structuralist thinking is that discourses and discursive practices provide subject positions. As many post-structuralist theorists have shown, 'individual access to subjectivity is governed by historically specific social factors and the forms of power at work in a particular society' (Weedon $1992,95)$. We view identity as central to learning. To become accepted members of dominant discourses, such as academic disciplines, individuals are required to act, think, speak and write within the discipline's ideological frameworks (Gee 1990). This poses particular difficulties for first-generation students and/or those who are not fully proficient in English, and who come from print-impoverished home backgrounds and schools which have not facilitated close, critical engagement with texts (Kapp 2004; van Pletzen 2006). It is assumed that students should be assimilated into the culture of the institution, and in general, higher education institutions tend to construct students' home identities and languages as problems that have to be fixed. What is hidden from the institution is that becoming proficient in the dominant discourse entails negotiating values, attitudes and beliefs substantially different from their home discourses, resulting in students often having to deal with challenging tensions around identity. 
Nevertheless, while discourses provide powerful ideological frameworks, many researchers have argued that individuals are not necessarily overdetermined by discourses (Christie 2008). Individuals who have agency may take up a variety of positions within different discourses, which may overlap and even conflict. Individuals invest in certain subject positions rather than others at particular times in relation to structures of power, interactions with others, emotions and opportunity (Norton 1997). In order to understand why students succeed or fail, we need to take their past identities into account and we need to understand how students 'invest' in their learning and when, where and why individuals engage (or disengage) with 'socially and discursively available resources' (Thomson 2009, 160).

\section{Methodology}

The study explored a micro-educational setting (students from the Intervention Programme). Semi-structured interviews were conducted with the 13 first-year students from January to March, 2010, followed by a focus group session in June 2010. The students also filled in background questionnaires about their homes, neighbourhoods and school environments and wrote reflections on their language and mathematics histories. The interviews explored students' schooling experiences, their experiences during the first six months in the academic mainstream and their subsequent experience of being placed in the Intervention Programme after they had failed the first semester. The focus group concentrated more intently on their classroom learning experiences, particularly their experiences of problem-based learning. 3

Analytical induction was used to uncover categories and themes within the set of interview and focus group data. Using a coding system to organise the data, the researchers assigned categories by clustering similar ideas and then assigning themes to the data. Themes can be described as unifying concepts that emerge from the data to provide more general insights (Boyatzis 1998; Ryan and Bernard 2003). Once the themes had been identified, they became significant in linking substantial portions of the interviews together (Morse and Field 1995).

Our research does not assume that we can read off students' identities from the interviews. As many writers have shown, participants reconstruct their identities during the interview process (see, Sfard and Prusak 2005; Thomson 2009). We are interested in the issues that the participants choose to foreground, how they wish to be viewed and how they re-position themselves. In the words of Holland et al. $(1998,3)$, 'People tell others who they are, but even more importantly, they tell themselves .... In analysing the interviews, we found Sfard and Prusak's $(2005,18)$ notion of 'designated' identities useful. They argue that 'designated identities give direction to one's actions and influence one's deeds to a great extent, sometimes in ways that escape rationalization'. Our participants' very strong sense of 'designated' identities as doctors in the 'new' South Africa, seemed to play a crucial role in the ways in which they re-positioned themselves in order to survive.

\section{Negotiating home and school}

I was the top learner in my region, in the circuit ja, so in the province we were given awards. 
From the data it appears that students arrived at the university with an identity based on their cultural backgrounds, as well as on being high academic achievers. They positioned themselves as top students from (what they perceived to be) good schools, where they had worked extremely hard.

Eleven of the participants in this study grew up in working-class townships and rural areas and were the first generation to have the opportunity to attend university. The other two participants had parents who were employed in a professional capacity, which enabled them to live in more middle-class environments. Apart from two participants who grew up with both a mother and father, all participants grew up in extended families as a result of the death or separation of their parents.

All participants commented on the strict discipline used by teachers, with some mentioning corporal punishment as a regular occurrence. One participant had been expelled from school for having had a boyfriend and had been forced to apologise to the entire school in order to resume her studies the following year. Participants also commented on the pivotal role that religion had played in their schooling years. It appears that religion was used to instil a very strict moral code. Only one participant felt that her school was very well resourced, while others mentioned that their schools either lacked resources such as computers and laboratories, or that these resources were not optimally utilised:

Okay, from my school environment there weren't . . . any resources, like for example we did not have a Physics lab, we didn't have water, the toilets were messed up ...

Even though they had found the discipline overly strict and commented on lack of resources, all participants viewed their schools as good institutions. Students generally positioned their teachers as people who worked in solidarity with them to enable them to overcome the barriers to learning in the environment:

My high school was regarded as one of the best in the township, ja it was a good school there and the discipline was quite high ... We had computer labs and Science labs, but in our Science labs we did not do much experiments, (. . . .), but ja, it was a good school, the teachers were good...

In a similar vein, although English is a second language for the participants, all had attended schools where the official medium of instruction was English. But, as is generally the case in South Africa, the majority of them reported that teachers used their home languages in the classroom in order to facilitate students' understanding.

All participants appeared to have been highly motivated during their final year of school. They had generally surrounded themselves with high-achieving friends, worked in study groups and attended extra lessons where possible. It is evident from their narratives that the students had shown considerable agency in their success at school and in gaining admission to study Medicine despite the structural constraints of their backgrounds. As a result, they had received substantial recognition and support in their schools and communities. Walker $(2006,7)$ writes that 'processes of learning and agentic identity formation are intrinsically connected with the process of recognition. By receiving recognition from (significant) others, one achieves a confident and positive identity'. The students arrived at the institution confident 
about their potential to succeed and with a strong sense that they would act as resources for their families and communities in the future.

The legacy of the Apartheid history of racial and ethnic separation is such that students from working-class backgrounds still tend to come from relatively geographically separate, relatively homogenous school and neighbourhood environments where mobility is constrained and where they would have had little exposure to the implications of disparity in wealth. In general, students expressed excitement about the diversity and the possibilities of transcending conventional racial and ethnic boundaries:

I had never in my life experienced such an amazing experience, people of all cultures, from different places, different behaviours, languages, everything Á they create a space for you to be able to understand other people and what they do, so it was amazing ... .

As part of the Faculty's attempt to move away from the stigma attached to separate support programmes for students from disadvantaged backgrounds, as well as its attempt to use student diversity as a resource in the learning environment, the students were admitted to the mainstream alongside students who had been high achievers in the most elite schools in the country. The students were therefore positioned by the institution to succeed in the mainstream.

\section{Negotiating difference in the mainstream}

In their interviews, the students reported that they had assumed that their identities as hard-workers would sustain them:

I thought it would be really easy because I am doing something I am ready for, the same as high school and I would work as hard as when I was in high school . . . .

However, within the first few weeks of the semester, they discovered that they did not have the necessary academic, cultural and linguistic resources to decode and interpret the discourses of their new context:

It was a huge transition. Yooo, I think after two months, I was like, I am away from my mother, I am away from my community, I am away from my teachers, teachers who used to be behind me every single day. (. . .) I was like, so what is wrong with me because I try as much as possible to stay positive, I went to church, I was like, God, if there is something I am not doing right, please show me the right way, because I have no idea what is going on, I studied, and I still failed ...

The students soon realised their underpreparedness in comparison with firstlanguage English speakers who came from well-resourced backgrounds. They worked out that the rote learning and instrumental spoon-feeding practises that had been encouraged by teachers were inappropriate learning tools in the new environment, but, they had little sense of alternatives:

... teachers were like helping you to pass pass pass and you would like pass with flying colours .... When I was in school I was in control of my work, I knew what to do at 
what time and how to do it. Here (at university) it is like sometimes you don't know how to do it ...

As a consequence of their schooling and of their struggles with English, students particularly struggled to connect to the problem-based approach to learning which had been designed to discourage rote learning, and foster self-directed learning and metacognitive skills (such as problem-solving and critical reasoning) in order to facilitate lifelong learning (Harland 2003). The problem-based learning model operates on the basis of small groups and positions students as equal participants in the learning context. The aim is to allow students to draw on and acknowledge their prior knowledge, and to identify gaps in their learning with the help of a facilitator. This means that students are required to participate in learning sessions at cognitively demanding levels. They have to be active participants as the group itself is expected to generate learning objectives. Each student constructs his or her own meaning based on an interaction with prior learning and current experiences (Harland 2003). With the guidance of a facilitator, students are expected to investigate relationships between ideas, apply theory to practice, use evidence-based arguments and engage in the validity of multiple conclusions.

Both in the individual and focus group interviews, participants foregrounded the problem-based learning sessions as a site of humiliation. Many had been intimidated by the fluency of their fellow participants and had consequently been silent throughout the sessions. One participant remarked that problem-based learning sessions were a 'monster' where he often used to 'shake' when he was forced to speak up. Students also commented that the interaction occurred at a speed which made it hard to listen, reflect and compose. Participants described how the process made them feel 'exposed' and 'run down', as they could not relate to the rest of the group, who seemingly participated with ease.

As a consequence of what participants perceived as a 'language barrier', they felt that they did not have the right to 'correct' other people, for they viewed themselves as 'the least in the group'. As one participant remarked, 'so if the good speakers say that something is right, you just have to accept it, you cannot challenge'. This caused participants to become demotivated and isolated, with the result that they did not benefit from the central vehicle of learning used in the medical curriculum. It appears that participants' schooling background did not prepare them well for a learning situation where they had to challenge the views of others and engage in 'critical reasoning'. Many failed their first assessment because, following school literacy practices where teachers delineate relevant content through summary notes and worksheets (see Kapp 2004), they ignored the textbooks, believing that 'answers were in the lecture notes'.

Many participants also spoke of their struggles to come to grips with a dominant culture with substantially different norms and values from their own. In this respect, participants mentioned a wide range of issues, including being exposed to alcohol or drug abuse by other young people; observing other students being disrespectful to lecturers; different dress codes; different religious views and the lack of enforced codes of behaviour.

It is apparent that while students celebrated institutional diversity in the abstract, they experienced 'difference' in negative terms and felt marked as 'other'. Participants were very conscious of their racial identity and remarked on subtle forms of racial tension experienced during their first months at university. This 
ranged from being 'invisible' to white students; to observing students segregate themselves along racial lines and to racial stereotyping:

\begin{abstract}
We were sitting at a table and this girl was talking about how she took a taxi . . . and then the friends kept on referring to the taxi as a black taxi. Every white person at the table took turns saying it and they did not want to stop. Well it upset me a lot because I did not think racial things still exist, even though I know it exists, and people do it to make a person feel small deliberately when we are trying to put it behind and people are still trying to go back to the past...
\end{abstract}

Students' experiences both within and outside of the classroom resulted in considerable demoralisation. Nevertheless, when asked in the focus group interviews whether they would have preferred a different learning method, or whether they would have preferred problem-based learning groups to be less diverse, they, surprisingly, all argued that, if the groups had been less diverse, they would not have been able to learn from one another, as one cannot learn in groups where, in the words of one participant, 'everybody is scared'. One participant remarked that he used to look forward to working with 'brilliant people, like white people, but I never had that privilege, so I was looking forward to it, so it was going to be denied from me if I was just with my own'. It appears that students had conflated whiteness with English fluency and brilliance (see also Bangeni and Kapp 2007). In their individual interviews, every student said that they would not have preferred to study in their home tongue. Typically, students said that 'it is only through English that we can learn medicine'.

Gee (1990) argues that primary (home) discourses provide subject positions which always seem natural and neutral until one's self-concept is challenged by movement away from home and encounters with secondary discourses which offer new subject positions. It seems that, in the light of their experiences within the academic and social environment, students reinterpreted their school and home identities of being confident, agentic high achievers and reconstructed these identities in deficit terms. They regarded 'white', English home language speakers as 'successful students' and assumed that they would need to assimilate, in order to survive. Participants appeared to feel quite strongly that, although they had to shift their own sense of self to survive in a different academic culture, they wanted to be challenged to reach a 'higher standard'. As one participant put it, 'We got exposed to a new environment where we can learn. There is no other way, we just have to go through it'.

\title{
Negotiating failure
}

I was embarrassed about it because I never failed anything, I cried about it for a week.

It is clear from the data that students were devastated when they were told that they had failed the first semester and that they would be required to discontinue with their current studies in the mainstream, and instead enter an academic support (Intervention) programme for a year. Both in the individual and focus group interviews, students described how they struggled to come to terms with occupying the subject position of 'failure'. A number of students considered leaving Health Sciences or university, both because of practical considerations such as finances and because they had lost confidence in their own intellectual capacity. One participant commented: 
I wanted to drop Medicine . . . because when that happened I remembered my headmaster's words, like he always used to say like not everyone is meant for education, maybe you may be good in sports so you should do sports and if you good in music and you not very gifted when it comes to academics, you should try and find where exactly you fit it, so ... so I was thinking that maybe if I changed courses it would be better there, I would be able to cope....

It appears that this participant had to realign her previous 'designated' identity as a future doctor, and her view of all the skills and talents that had accompanied this dream, with the possibility of a very different future.

Many students expressed a strong sense of being disappointed in themselves for having 'wasted' time and resources, while a number of students felt misled by a system that had initially accepted them, and had (in their view) therefore positioned them as students who could succeed in becoming doctors:

I felt betrayed by everyone and everything there was, I didn't want to give up but I felt like I didn't know if I could carry on, if I would be able to continue . . .

One of the biggest challenges for the students was how to face friends, teachers and family who still held them in high esteem, in their new role of 'failed student':

\begin{abstract}
When I was at home I . . . was invited at my school to help during winter school and we were encouraging those learners to do well and then they see me as a role model and I was kind of like ashamed to even encourage other learners because like I know how I did at school . . . people had high expectations from me . . I was hoping for higher marks but I never thought like I will fail . . ., ja but I had to accept it but when I came back here, it was different because . . I I had to go through the whole experience again because when I see myself being divided from the mainstream class and all those, that's like when it started to get real . . . it seems like it's an attack, some kind of a depression, it comes back again and then I have to battle with it again ...
\end{abstract}

This quotation provides a poignant comment on the crisis described by many students. It also highlights a common theme in the data, which is that, despite students' difficulties, which included failing assessments; they had not asked for help and had still expected to pass the final examinations. Failing came as a shock. In their case study of Engineering students from disadvantaged backgrounds, Case and Marshall (2008) have written about a similar inclination for working-class students to declare that there is no problem despite evidence to the contrary. In the wake of difficulty, most students had turned to religion as a guiding framework that allowed them to 'stay positive'. Religion seems to act as a 'sponsor' for their actions by offering a social identity which facilitates security, connection and agency (Herrington and Curtis 2000, 369; see also, Bray et al. 2010).

\title{
Negotiating the Intervention Programme
}

My mom was telling me how [the university] had called them and they said that I was a weak student, I personally took offence to that, I was like Á 'what? They said what, I'm a weak student, what? I'm going to show them. And my mom ... [said] 'show them? You are not going back to Cape Town'. But I . . . [said],' I'm going back to Cape Town, it's not even up for discussion, I am going back . . . 
Once students came to terms with the fact that they had to enter the Intervention Programme in order to continue with their studies, they seemed to draw on family and religion to reposition themselves as survivors:

Wow, gosh, you failed, but that doesn't mean you are a failure, it just means that you have to take a different path to what others are taking Á and I had to change perspective on it ...

The Intervention Programme differs from the mainstream course in that the class is smaller and there is much more individual attention from lecturers. Students' understanding of basic concepts and terminology is mediated by a systematic, scaffolded approach (see, Wood, Bruner, and Ross 1976). At the end of the programme, the expectation is that students will be able to transfer and implement skills, knowledge and attitudes to other study areas (Alexander, Badenhorst, and Gibbs 2005).

From the focus group discussion at the end of the Intervention Programme, it seemed that students had started to internalise the benefits of being in a smaller learning environment with other students who were at a similar level:

[I]n IP [Intervention Programme] we have common characteristics, we all need improvement, so we are like free to relate to one another, we have common problems, so it makes it better to study, we are a family ... .

In the focus group interview, students said that they were able to develop a speaking position, to 'stand their ground'. They talked about how they quoted sources and challenged other viewpoints and spoke of how they no longer relied on rote-learning. They seemed to recover the agentic behaviour that characterised their schooling and became more confident to consult lecturers, textbooks, form study groups and make use of resources, such as online learning systems and the library.

After one year in the Intervention Programme, students who pass their examinations, return to the mainstream to complete the second half of their first year. Despite students newly found confidence, they expressed high levels of fear and apprehension about their return. In the focus group discussion just prior to their return, participants were concerned about how mainstream students would view them, and whether they would be accepted. One participant remarked, 'we are not like them, there is a distinction between us. Will they accept me?'

\section{Discussion}

'Black' students are entering the institution in a moment of societal transition that offers them previously unheard of possibilities for upward mobility. However, as the data show, 'black' students entering into a predominantly 'white' English-medium institution have to negotiate considerable tension and ambivalence in relation to language, values, attitudes and beliefs, as well as everyday behavioural norms. Across the globe, research has shown that working-class students experience various forms of alienation within the middle-class environment of higher education (see, for example, Herrington and Curtis 2000; Reid, Archer, and Leathwood 2003; Mann 2008; Christie et al. 2008). However, within South Africa, the systematic poverty, the legacy of structural injustice, the fracturing of family life and pervasive violence have 
meant that 'black' learners growing up in working-class contexts have continued to be placed in situations of extreme vulnerability (see Ramphele 2002; Swartz 2009; Bray et al. 2010). Educational theorists like Bloch (2009) and Soudien $(2007,191)$ have shown that 'the social rhythms and regimens' of working-class school environments 'operate weakly and often capriciously' with very marked inequality in educational outcomes among schools which still correspond to racial categories. All of this means that students' transition into higher education involves bridging a considerable sociocultural, academic and linguistic chasm.

The Health Sciences Faculty has excellent mentoring and academic support services in place for first-year students. Nevertheless, it appears from the narratives, that although the students were high achievers and exhibited high levels of agency within their home contexts, they did not ask for help from staff or students within the university context. Instead, they preserved 'face', mimicking the rituals associated with being a well-adjusted student, placing faith in hard work, religion and in the 'can do' (Thomson 2009, 1) attitude and the survival strategies that had worked at school.

The Faculty has structured the teaching and learning environment to promote diversity and critical engagement among students. The curriculum is embedded in the South African primary healthcare context. Many of the case studies in the curriculum are drawn from sociocultural contexts with which the students are familiar. And yet, the students could not access the material, linguistic, social and cultural resources that would enable them to participate in, and benefit from, the environment (see also van Pletzen 2006). The problem-based learning model entails using language in decontextualised, cognitively demanding situations (Cummins 1996). Students were required to distil information, formulate arguments and participate in intellectual exchange in ways that had not been part of their school learning backgrounds. As the data show, they ended up resorting to silence and to the learning habits that had worked at school. They re-positioned themselves in deficit, outsider terms.

The data suggest that one cannot assume that high-achieving students from disadvantaged backgrounds will easily be able to negotiate the discursive shift in the school to university transition. While integration and diversity are crucial values to aspire to in the process of post-Apartheid nation-building, the students' experiences suggest that there has been insufficient attention paid to the ways in which discourses are made explicit and the ways in which access to powerful dominant discourses are mediated. Despite students' own desire to embrace diversity, their silence in class and descriptions of racial stereotyping suggest that the goal of using diversity as a resource was not achieved.

Crucially, in a period of social change, it is equally important to question the 'taken-for-granted' institutional culture. Students' transitions need to be mediated in ways that take their differential past teaching and learning experiences into account and foster a sense of belonging and connectedness to the institution through transformation of classroom and institutional culture. Not doing so, runs the risk of instilling a benign multiculturalism that simply reproduces dominant discourses and power relations, and silencing and/or placing the burden on individuals to assimilate. As the data show, the emotional toll of negotiating identity and learning is considerable. 


\section{Acknowledgements}

Funding from the Andrew W. Mellon Foundation is gratefully acknowledged. We are grateful to Bonani Dube and Judy Sacks for conducting the interviews with students.

\section{Notes}

1. This name is a pseudonym. It is impossible to contextualise fully the imbrications of South African language and educational backgrounds without using the Apartheid-era racial classification. However, to signify our own beliefs that these categories are to some degree at least, artificially constructed, we will use quotation marks. In this paper, we use the category 'black' inclusively to refer to 'African', 'Coloured' and 'Indian' students.

2. The programme will be described in more detail below.

3. Problem-based learning forms the central learning vehicle for first-year medical students at this university.

\section{References}

Alexander, R. L., E. S. Badenhorst, and T. Gibbs. 2005. "Intervention Programme: A Supported Learning Programme for Educationally Disadvantaged Students." Medical Teacher 27 (1): 66 Á70.

Bangeni, B., and R. Kapp. 2007. "Shifting Language Attitudes in a Linguistically Diverse Learning Environment." Journal of Multilingual and Multicultural Development 28 (4): 253 Á270.

Bloch, G. 2009. The Toxic Mix: What's Wrong with South Africa's Schools and How to Fix It? Cape Town: Tafelberg Publishers.

Bourdieu, P. 1991. Language and Symbolic Power. Cambridge, MA: Harvard University Press.

Boyatzis, R. 1998. Transforming Qualitative Information. Thousand Oaks, CA: Sage.

Bray R., I. Gooskens, S. Moses, L. Kahn, and J. Seekings. 2010. Growing up in the New South Africa: Childhood and Adolescence in Post-apartheid Cape Town. Chapters 5 and 6. Cape Town: HSRC Press

Case, J., and D. Marshall. 2008. “The 'No Problem' Discourse Model: Exploring an Alternative Way of Researching Student Learning." International Journal of Educational Research 47 (3): 200 Á207.

Christie, P. 2008. Changing Schools in South Africa: Opening the Doors of Learning. Johannesburg: Heinemann.

Christie, H., L. Tett, E. Cree, J. Hounsell, and V. McCune. 2008. "A Real Rollercoaster of Confidence and Emotions: Learning to Be a University Student." Studies in Higher Education 33 (5): 567 Á581.

Cummins, J. 1996. Negotiating Identities: Education for Empowerment in a Diverse Society. Ontario: California Association for Bilingual Education.

Gee, J. 1990. Social Linguistics and Literacies: Ideology in Discourses. London: Falmer Press.

Harland, T. 2003. "Vygotsky's Zone of Proximal Development and Problem Based Learning: Linking a Theoretical Concept with Practice through Action Research." Teaching in Higher Education 8 (2): 263 Á272.

Herrington, A., and M. Curtis. 2000. Persons in Process: Four Stories of Writing and Personal Development in College. Urbana, IL: National Council of Teachers of English.

Holland, D., W. Lachicotte, D. Skinner, and C. Cain. 1998. Identity and Agency in Cultural Worlds. Cambridge, MA: Harvard University Press.

Kapp, R. 2004. "'Reading on the Line': An Analysis of Literacy Practices in ESL Classes in a South African Township School." Language and Education 18 (3): 246 Á263.

Mann, S. J. 2008. Study, Power and the University. Maidenhead: Society for Research into Higher Education \& Open University Press.

Morse, J. M., and P. A. Field. 1995. Qualitative Research Methods for Health Professionals. Thousand Oaks, CA: Sage. 
Norton, B. 1997. "Language, Identity and the Ownership of English." Tesol Quarterly 31 (3): $409 A ́ 430$.

Oberprieler, G., K. Masters, and T. Gibbs. 2005. "Information Technology and Information Literacy for First Year Health Sciences Students in South Africa: Matching Early and Professional Needs." Medical Teacher 27 (7): 595Á598.

Olckers, L., T. J. Gibbs, and M. Duncan. 2007. "Developing Health Science Students into Integrated Health Professionals: A Practical Tool for Learning." Medical Education 7: 45Á52.

Ramphele, M. 2002. Steering by the Stars: Being Young in South Africa. Cape Town: Tafelberg Publishers.

Reid, B., L. Archer, and C. Leathwood. 2003. "Challenging Cultures? Student Conceptions of 'Belonging' and 'Isolation' at a Post-1992 University." Studies in Higher Education 28: 261 Á277.

Ryan, G. W., and H. R. Bernard. 2003. "Techniques to Identify Themes." Field Methods 15 (1): 85Á109.

Sfard, A., and A. Prusak. 2005. "Telling Identities: In Search of an Analytic Tool for Investigating Learning as a Culturally Shaped Activity." Educational Researcher 34 (4): 14 Á22.

Sikakana, C. N. T. 2010. "Supporting Student-doctors from Under-resourced Educational Backgrounds: An Academic Development Programme.” Medical Education 44: 917 Á925.

Soudien, C. 2007. "The 'A' Factor: Coming to Terms with the Question of Legacy in South African Education." International Journal of Educational Development 27 (2): 182Á193.

Swartz, S. 2009. Ikasi: The Moral Ecology of South African Township Youth. Johannesburg: Wits University Press.

Thomson, R. 2009. Unfolding Lives: Youth, Gender and Change. Bristol: The Policy Press. Van Pletzen, E. 2006. "A Body of Reading: Making 'Visible' the Reading Experiences of Firstyear Medical Students." In Academic Literacy and the Languages of Change, edited by L. Thesen and E. Van Pletzen, 104Á129. London: Continuum.

Walker, M. 2006. "Identity, Learning and Agency in Higher Education." Paper presented in the Interdisciplinary Colloquium Identity and Learning, University of Stellenbosch and University of Cape Town, Cape Town, March 30Á31.

Weedon, C. 1992. Feminist Practice and Poststructuralist Theory. Cambridge: Blackwell.

Wood, D., J. Bruner, and G. Ross. 1976. "The Role of Tutoring in Problem Solving." Journal of Child Psychology and Psychiatry 17 (1): 89Á100. 